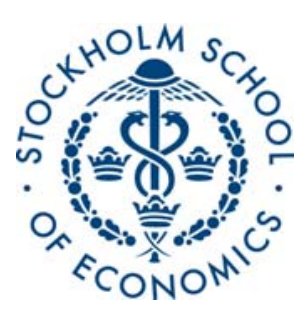

\title{
FINANCIAL MARKETS IN EAST ASIA AND EUROPE DURING THE GLOBAL FINANCIAL CRISIS
}

Anders C. Johansson

Stockholm School of Economics

\section{CERC Working Paper 13}

January 2010

Postal address: P.O. Box 6501, S-113 83 Stockholm, Sweden.

Office address: Holländargatan 30 Telephone: +46 87369360 Telefax: +46 8313017

E-mail: japan@hhs.se Internet: http://www.hhs.se/cerc 


\title{
Financial Markets in East Asia and Europe during the Global Financial Crisis
}

\author{
Anders C. Johansson* \\ Stockholm School of Economics
}

\begin{abstract}
This paper analyzes equity market movements in East Asia and Europe during the global financial crisis. Extending the methodology in Chakrabarti and Roll (2002), we study regional as well as country-regional volatility, covariance and correlation. We also analyze regional and country-regional tail dependence in the two regions. The results show that volatility and covariance patterns in East Asia and Europe were relatively stable until the second half of 2008. Correlations were higher in Europe, but relatively high in East Asia as well. Both regions thus exhibit an overall increase in comovements compared to the time of the Asian financial crisis. There was a sharp decline in regional correlation during the third quarter of 2008 in both East Asia and Europe, which was then followed by a strong increase. The spread of the crisis affected Europe more, with resulting higher regional comovements. Moreover, average tail dependence stayed relatively stable in both regions throughout the pre-crisis and crisis periods with a notably higher level of tail dependence in Europe. Surprisingly, countries in East Asia such as China that are usually seen as insulated from the rest of the region show signs of increasing market integration with the rest of the region. The increasing level of financial market integration and the high level of comovements during times of international financial turmoil demonstrate the limited benefit of diversification in regional portfolios.
\end{abstract}

JEL Classification: F36; F41; G15

Key Words: East Asia; Europe; Financial crisis; Financial integration; Correlation; Copula; Tail dependence

\footnotetext{
* ANDERS C. JOHANSSON, Stockholm School of Economics, P.O. Box 6501, SE-113 83 Stockholm, Sweden. Phone: +46-8-736 9360. Fax: +46-8-31 30 17. Email: anders.johansson@hhs.se. The author is grateful for helpful comments and suggestions from participants at the ACE International Conference organized by the APEC Study Center at the City University of Hong Kong in December 2009. Financial support from the Bank of Sweden Tercentenary Foundation, the Swedish Foundation for International Cooperation in Research and Higher Education, and the Swedish School of Advanced Asia-Pacific Studies (SSAAPS) is gratefully acknowledged.
} 


\section{Introduction}

When the Asian financial crisis erupted in July 1997, an increase in regional financial market comovements followed. Even though the regional increases in covariances and correlations were the largest in East Asia during this period, similar increases occurred in Europe as well (Chakrabarti and Roll, 2002). Numerous studies have shown that financial crises tend to spread across country borders and financial markets often move more closely together during such episodes. However, each financial crisis is unique in its own way, and the recent financial crisis originating in the US subprime market is no exception. While there are a number of different explanations for the Asian financial crisis, most economists seem to agree that excessive lending practices in the US property market combined with a rapid expansion of complex financial products were among some of the main reasons behind the recent crisis. These financial products typically bundled, among other things, mortgages together and made it more difficult to value them and resulted in banks relaxing their lending practices even more. The spread of the subprime crisis is also different from previous crises. Originating in the subprime sector, it soon spread through the US financial system and then onward to the European financial sectors, where financial institutions were exposed to the sudden and severe increase in defaults. Most Asian countries, on the other hand, have primarily been affected through real economy channels rather than via a spread among countries' financial sectors. Not only developing countries such as China, Thailand and Vietnam but also advanced countries including Japan were affected by sudden shortfalls in their previously booming export sectors. However, even though the spread of the crisis has occurred through different channels, it has affected firm values in most countries around the world. This raises some important questions for policymakers and international investors alike: How closely are regional financial markets related? Is there a significant difference between market integration 
in Europe and Asia? If such a difference exists, is it similar to the differences seen during the Asian financial crisis, or are we witnessing a different evolution of dynamic regional market linkages?

In this paper, we incorporate both time-varying correlations and time-varying copulas to analyze the dynamic nature of regional financial market integration in Europe and East Asia. Three main features of this study separate it from Chakrabarti and Roll (2002) and other related studies. First, we focus on the recent global financial crisis that started in the US. Second, we add copulas and tail dependence analysis. This improves our understanding of dependence structures across regional equity markets. Third, we extend Chakrabarti and Roll's original methodology by looking at how each country relates to the rest of its region. This enables us not only to look at regional market integration, but also to determine which countries experience the most significant changes in terms of regional comovements in times of global financial turmoil. Besides comparing and extending Chakrabarti and Roll's initial results on the Asian financial crisis to the current crisis, this paper complements initial studies on the overall effects of the current crisis on global equity markets. For instance, Bartram and Bodnar (2009) take a broad view of the impact of the crisis on global equity markets. Their focus is mostly on the direct effect in terms of stock price declines, even though they also include a preliminary discussion on market correlations.

Our findings show that regional volatility and comovements differ from those during the Asian financial crisis. Europe is more affected during the global financial crisis with higher volatility and covariance. However, regional correlation in East Asia also increased quickly from an initial low level at the onset of the crisis. Overall, the correlation patterns indicate increased levels of comovements during the crisis period compared to the pre-crisis period. Regional tail dependence remains relatively stable in both regions, with Europe exhibiting a much higher level of average tail dependence both before and during the crisis. A number of 
markets experience a strong downturn in average tail dependence during 2008 , followed by an equally fast and strong increase. The results have important implications for investors who seek to diversify their regional portfolios. While diversification is usually seen as beneficial for international investors, our findings indicate that the benefits of such diversification have been of limited value during the global financial crisis. As financial integration increases, markets move more closely together. This limits the ability to decrease portfolio risk by diversification across markets. The results show that this is true for both East Asia and Europe during a crisis that actually started out as far away as the US.

The rest of the paper is structured as follows: Section 2 discusses related literature, focusing on time-varying market integration and previous research on contagion effects during times of financial crisis. Section 3 describes the methodology. Section 4 first introduces the data and then presents the empirical results. Results are discussed on a regional as well as country-regional level. Finally, Section 5 concludes the paper and offers some suggestions for future research.

\section{Related Literature}

This paper relates to several different strands of the research literature on international financial markets. First, it builds on the literature on financial market integration (e.g. Solnik, 1974; Stehle, 1977; Stulz, 1981; Jorion and Schwartz, 1986; Eun and Janakiramanan, 1986; Harvey, 1991; Bailey and Jagtiani, 1994; Carrieri, Errunza, and Hogan, 2007). Market integration has direct implications for international investors and their ability to diversify their portfolios. One of the most influential studies in this area is that of Bekaert and Harvey (1995). They study a number of both developed and emerging markets and find that even emerging markets, such as several of the ones included in this study, can show higher levels of integration even though they are commonly seen as insulated from the rest of the world. In a 
related study, Johansson (2009b) looks at China's financial market integration with the world. Using monthly data over the period 1991-2008, he finds that China's equity market has been quite isolated from the rest of the world, but that there seems to be a change taking place during recent years. Also, Johansson and Ljungwall (2009) look at correlation and spillover effects among the markets in the so-called Greater China region (China, Hong Kong, and Taiwan). They find some indications of spillover effects between the mainland and the two more advanced markets. However, the relationship between Hong Kong and Taiwan is stronger with a much higher correlation between the two. When it comes to East Asia as a region, Eichengreen and Park's (2005) findings indicate that the East Asian financial markets tend to be more closely related to markets in the US and Western Europe than other markets in the region. Studies on other asset classes have also identified significant regional relationships in East Asia. For example, Johansson (2008) focuses on four bond markets in East Asia. He finds that they exhibit significant spillover effects as well as time-varying and at times high correlation.

Besides general studies on market integration and correlation, there are studies that focus on financial crises and contagion effects. Many of these studies base their analysis on correlation as well, thus making their approach close to general studies on financial market integration. One example from this literature is Baig and Goldfajn (1998) who argue that a rise in correlation during times of financial turmoil is an indication of contagion. Several studies have argued that correlation is a poor measure for contagion (e.g. Forbes and Rigobon, 2002). Similarly, Carrieri, Errunza, and Hogan (2007) argue that correlation is not a satisfying measure for financial market integration, as it tends to underestimate the degree of integration. Rodriguez (2007) instead proposes the use of copulas when analyzing changes in the dependence structure among different markets and contagion effects during times of financial 
crisis. He finds evidence of considerable changes in the dependence structure among different markets during periods of turmoil.

\section{Methodology}

\section{a. Regional Movements}

In this study, two different approaches are used to measure regional comovements. First, we follow Chakrabarti and Roll (2002) and compute the geometric mean of absolute values of the covariance between every pair of countries in each of the two regions:

$$
\gamma_{r, t}^{\mathrm{cov}}=\left(\prod_{i<j}^{m}\left|\operatorname{cov}_{i j, t}\right|\right)^{1 /[m(m-1) / 2]}
$$

where $\gamma_{r, t}^{\text {cov }}$ is the measure for the covariance in region $r$ at time $t, \operatorname{cov}_{i j, t}$ is country $i$ 's covariance with country $j$, and $m$ is the number of countries in the region (i.e. $m=10$ ). The same approach can be used to compute a measure for regional correlation and regional standard deviation:

$$
\begin{gathered}
\gamma_{r, t}^{\rho}=\left(\prod_{i<j}^{m}\left|\rho_{i j, t}\right|\right)^{1 /[m(m-1) / 2]}, \\
\gamma_{r, t}^{\sigma}=\left(\prod_{i<j}^{m}\left|\sigma_{i j, t}\right|\right)^{1 / m} .
\end{gathered}
$$

Here, $\gamma_{r, t}^{\rho}$ is the average correlation in region $r$ at time $t$ and $\gamma_{r, t}^{\sigma}$ is the average volatility in region $r$ at time $t$. The three measures for regional movements are thus geometric averages of the absolute values of country-specific movements. 


\section{b. Country-Regional Correlation}

Chakrabarti and Roll (2002) provide an interesting study of the financial markets in Europe and East Asia during the Asian financial crisis. However, they do not analyze the relationship between regional and country-specific movements during that period of financial turmoil. Here, we therefore choose to extend their methodology to allow for an in-depth analysis of how each country relates to the rest of its region during the global financial crisis that erupted in 2007. To allow for a country-specific analysis, we choose to compute the arithmetic average of the correlation between country $i$ and each of the other countries in the region in which country $i$ resides. That is, we compute the following measure for country-region correlation:

$$
\gamma_{i r, t}^{\rho}=\frac{1}{J} \sum_{j=1}^{J} \rho_{i j, t}, \quad i \neq j
$$

The reason we use the arithmetic average for each country is that we want to allow for potentially negative correlations between a country and the rest of the region. ${ }^{1}$

\section{c. Estimating Tail Dependence}

To measure the tail dependence between two markets, we need to use a different approach from that of standard correlations. Here, we introduce copulas and how they can be used to analyze dependence between two or more variables. ${ }^{2}$ While we limit the discussion to the bivariate case, it is easily extended to a multivariate setting. Sklar's theorem for copulas says that if we let $F_{12}$ be a bivariate joint distribution function, we can decompose it into its marginal distributions, $F_{1}$ and $F_{2}$, and its dependence function (or copula):

$$
F_{12}\left(x_{1}, x_{2}\right)=C\left(F_{1}\left(x_{1}\right), F_{2}\left(x_{2}\right)\right) \text {. }
$$

\footnotetext{
${ }^{1}$ We also computed geometric averages of the country-region correlations, which resulted in very similar patterns. We only report the arithmetic averages for brevity.

${ }^{2}$ For a detailed introduction to copulas and their features, see e.g. Nelsen (1999).
} 
Here, the bivariate cumulative distribution function is decomposed. Correspondingly, we can decompose the bivariate density as:

$$
f_{12}\left(x_{1}, x_{2}\right)=f_{1}\left(x_{1}\right) \cdot f_{2}\left(x_{2}\right) \cdot c\left(F_{1}\left(x_{2}\right), F_{2}\left(x_{2}\right)\right) \text {. }
$$

If all the marginal distributions are continuous, then the copula is a bivariate distribution with Uniform(0,1) univariate marginal distributions. Equation (5) above can thus be used to obtain the joint distribution with given marginal distributions. The marginal distributions do not have to be similar to each other. Furthermore, the copula is not constrained by the marginal distributions.

We know that the standard measure of dependence, correlation, tend to vary over time for most financial variables. Similarly, we can assume that copulas change over time as well. Recently, a small but growing number of contributions in the literature on dependencies in financial markets have applied conditional copulas, that is, dependence measures that are allowed to vary over time. Patton (2006a) develops the theory for conditional copula when he analyzes the dependence structure between major exchange rates. He uses an approach similar to standard GARCH models (Engle, 1982; Bollerslev, 1986) to model and estimate the time-varying nature of copulas. Here, we focus on a copula that allows us to analyze the time-varying pattern in tail dependence, the so-called Symmetrized Joe-Clayton copula. The standard Joe-Clayton copula, introduced in Joe (1997) can be written as:

$$
C_{J C}\left(u, v \mid \tau^{U}, \tau^{L}\right)=1-\left(1-\left(\left[1-(1-u)^{\kappa}\right]^{-\gamma}+\left[1-(1-v)^{\kappa}\right]^{-\gamma}-1\right)^{-1 / \gamma}\right)^{1 / \kappa}
$$

Here, $\kappa=1 / \log _{2}\left(2-\tau^{U}\right), \gamma=-\log _{2}\left(\tau^{L}\right)$, and $\tau^{U} \in(0,1), \tau^{L} \in(0,1)$. The two parameters $\tau^{U}$ and $\tau^{L}$ measure the upper and lower tail dependence, respectively. Patton (2006a) proposes the following copula, which he calls the Symmetrized Joe-Clayton copula: 


$$
C_{S J C}\left(u, v \mid \tau^{U}, \tau^{L}\right)=0.5 \cdot\left(C_{J C}\left(u, v \mid \tau^{U}, \tau^{L}\right)+C_{J C}\left(1-u, 1-v \mid \tau^{U}, \tau^{L}\right)+u+v-1\right) .
$$

The main advantage of the modification is that it nests symmetry as a special case (when $\left.\tau^{U}=\tau^{L}\right)$. It is therefore fairly straightforward to test for asymmetry in tail dependence between two variables using the Symmetrized Joe-Clayton specification. Finally, to allow for the dependence to vary over time, Patton proposes the following evolution equations for the two dependence measures:

$$
\tau_{t}^{U}=\Lambda\left(\omega_{U}+\beta_{U} \tau_{t-1}^{U}+\alpha_{U} \frac{1}{10} \sum_{j=1}^{10}\left|u_{t-j}-v_{t-j}\right|\right)
$$

and

$$
\tau_{t}^{L}=\Lambda\left(\omega_{L}+\beta_{L} \tau_{t-1}^{L}+\alpha_{L} \frac{1}{10} \sum_{j=1}^{10}\left|u_{t-j}-v_{t-j}\right|\right)
$$

Here, $\Lambda(x) \equiv\left(1+e^{-x}\right)^{-1}$ is the logistic transformation which is used to keep the two dependence parameters in $(0,1)$.

To be able to estimate the copulas, we first need to estimate the marginal distributions for each of the different country indices. We apply Nelson's (1991) exponential GARCH (EGARCH) model that allows for asymmetry in volatility, a common feature in international equity markets. ${ }^{3}$ We also take potential serial correlation and fat tails into consideration by modeling the mean returns as autoregressive processes and by applying a $t$ distribution. Defining $R_{i, t}$ as the log-return of stock index $i$ at time $t$, the AR-t-EGARCH model can be written as:

$$
R_{i, t}=\mu_{i}+\sum_{n=1}^{N} \phi_{i n} R_{i, t-n}+\varepsilon_{i, t}
$$

\footnotetext{
${ }^{3}$ For example, Johansson and Ljungwall (2009) and Johansson (2009) show that several of the equity markets in the Greater China region exhibit asymmetry in volatility.
} 


$$
\begin{gathered}
\log \left(\sigma_{i, t}^{2}\right)=\omega_{i}+\sum_{l=1}^{q} \beta_{i l} \log \left(\sigma_{i, t-l}^{2}\right)+\sum_{m=1}^{p} \alpha_{i m}\left|\frac{\varepsilon_{i, t-m}}{\sigma_{i, t-m}}\right|+\sum_{k=1}^{r} \gamma_{i k} \frac{\varepsilon_{i, t-k}}{\sigma_{i, t-k}}, \\
\sqrt{\frac{v_{i}}{\sigma_{i, t}^{2}\left(v_{i}-2\right)}} \varepsilon_{i, t} \sim \text { iid } t_{v_{i}} .
\end{gathered}
$$

The estimation of the copula can be divided into three separate steps. First, we estimate each of the univariate distributions. Then, we apply a so-called probability integral transformation to the univariate standardized residuals, thereby transforming the univariate distributions into Unif $(0,1)$ distributions. Finally, we use the uniformly distributed variables to estimate the unconditional and conditional copulas with maximum likelihood (see Patton, 2006b, for more details).

Due to the number of markets in each region, the number of copulas is large. To analyze tail dependence in the region, we use a methodology that is similar to Chakrabarti and Roll (2002) but instead focus on regional tail dependence. One common approach to study tail dependence is to take the average of the upper and lower tail dependence, i.e. $\tau_{i j, t}=\left(\tau_{i j, t}^{U}+\tau_{i j, t}^{L}\right) / 2$. We use this average measure for tail dependence when we compute the geometric average for each region the following way:

$$
\gamma_{r, t}^{\tau}=\left(\prod_{i<j}^{m}\left|\tau_{i j, t}\right|\right)^{1 /[m(m-1) / 2]} .
$$

To get a better understanding of how each country relates to its region, we also compute the country-regional tail dependence by taking the arithmetic average of a country's tail dependence with all countries in the same region:

$$
\gamma_{i r, t}^{\tau}=\frac{1}{J} \sum_{j=1}^{J} \tau_{i j, t}, \quad i \neq j
$$




\section{Data and Empirical Results}

\section{a. Data}

Since we want to compare regional dependence structures during the financial crisis, we look at a comprehensive set of East Asian equity markets and match them with an equal number of Western European markets. The data set includes daily closing prices for a total of ten Asian equity markets: China, Hong Kong, Indonesia, Japan, Korea, Malaysia, Philippines, Singapore, Taiwan, and Thailand. The corresponding ten European equity markets are: Belgium, France, Germany, Italy, Netherlands, Portugal, Spain, Sweden, Switzerland, and the UK. In order to keep to a common currency, each country index is converted into a US dollardenominated index using the daily closing exchange rate for each country. Returns denominated in US dollars are then computed as $100 * \ln \left(P_{t} / P_{t-1}\right)$, where $P_{t}$ is the dollardenominated country index at time $t$. All the different time series are from Datastream. Due to the regional focus in our analysis, the limited differences in time zones across countries allow us to use daily data. It is difficult to pinpoint an exact date as the beginning of the crisis. For instance, the Lehman Brothers bankruptcy on September 15, 2008 is often mentioned as a critical date. However, it is obvious that the crisis began much earlier. This study looks at the development of the regional markets in East Asia and Europe as the crisis developed. We therefore choose an early starting date for the crisis and look at how volatility and dependencies change during the course of the crisis. In February and March 2007, more than 25 subprime lending firms went bankrupt as the declines in U.S. housing prices continued to accelerate. On February 27, the Dow Jones tumbled and fell 3.3 percent, the largest drop since September 11, 2001. We therefore set the starting date as February 27, 2007. To analyze the change in comovements, we collect data from January 1, 2004 to December 31, 2008. This gives us a total of 1305 observations, 823 before the onset of the crisis (822 return observations), and 482 after the crisis started. 
Table 1 provides summary statistics for the 20 equity markets. Summary statistics for each market are presented for both the pre-crisis period and the crisis period. All 20 markets exhibit positive mean returns before and negative mean returns during the crisis. Looking at the descriptive statistics, it is clear that the global financial crisis that erupted in the U.S. differs from the Asian financial crisis. Chakrabarti and Roll (2002) show that the European markets exhibited positive mean returns during the Asian financial crisis. Here, negative mean returns in the market coincide with the crisis, indicating that it spread to more markets. Furthermore, there is no significant increase in volatility with standard deviations during the crisis period roughly comparable to pre-crisis standard deviations. This is also different from the Asian financial crisis, during which the Asian markets exhibited strong increases in volatility during the crisis. The volatility also went up in the European markets during that period, even though the increase was significantly more modest in size. Skewness remained quite stable over the two periods, while kurtosis shifted significantly depending on market.

\section{[TABLE 1 HERE]}

Having discussed the basic features of the 20 markets, we now turn to the empirical results. We first apply the standard measurements developed by Chakrabarti and Roll (2002) and analyze the regional volatility, covariances, and correlations, respectively. We then use the alternative measure for country-regional correlations in order to better understand how each country relates to the rest of its region. Finally, we look at both regional and country-regional tail dependence.

\section{b. Regional Movements}

We first compute the regional geometric averages of volatility. The time-varying volatility patterns in the two regions are shown in Figures 1 and 2. The volatility patterns in the two regions are quite similar during the sample period. However, some differences are worth 
noticing. During the pre-crisis period, the average volatility in Europe is lower than volatility in Asia. As the crisis erupted during the first half of 2007, volatility in both Europe and Asia remained quite modest, although it increased steadily. European volatility did increase relatively more and reached the same level as that of Asian volatility during the second half of 2007. Finally, the sharp increase in volatility during the fourth quarter of 2008 was much larger in the European markets. After the Lehman Brothers bankruptcy in September, international financial markets experienced a general increase in volatility. However, the two figures show that market movements in Europe were much more volatile during that period. This indicates that the increase in market risk was more pronounced in Europe. If we compare these results with the findings in Chakrabarti and Roll (2002), the volatility patterns during the global financial crisis that began in 2007 are quite different from those of the Asian financial crisis. Regional volatility was significantly higher in Asia both before and during the Asian financial crisis. Overall, the pattern before the two crises erupted is thus similar. However, the change in volatility during the two crises is different in that the European markets only experienced a modest increase in volatility during the Asian financial crisis, but a much more pronounced increase during the global financial crisis in 2007-2008.

[FIGURE 1 HERE]

[FIGURE 2 HERE]

Average covariances in the two regions are presented in Figures 3 and 4. Europe exhibited a somewhat higher covariance during the pre-crisis period. As the crisis erupted in 2007, both East Asia and Europe experienced an increase in regional covariance. During the fourth quarter of 2008, there was a sudden and strong increase in regional covariance in both East Asia and Europe. However, the increase was much stronger in Europe, where the covariance reached a level more than twice the size of the covariance in East Asia. Comparing the results 
to Chakrabarti and Roll (2002), there is a significant difference in that the regional covariance in East Asia grew much stronger than that in Europe during 1998.

\section{[FIGURE 3 HERE]}

\section{[FIGURE 4 HERE]}

Figures 5 and 6 show the regional average correlation patterns. Overall, the correlation was higher for both regions compared to the findings in Chakrabarti and Roll (2002). The European markets show evidence of very high levels of comovements. Europe's correlation pattern was quite stable, hovering around a mean of approximately 0.8 . There was a decrease just before the onset of the crises, followed by an increase up to almost 0.9 . There was also a sharp decrease during the second half of 2008 , followed by an equally sharp increase in correlation towards the end of the same year. East Asia's correlation pattern is somewhat more volatile. Starting out with a very modest level of regional correlation during the pre-crisis period, correlation then increased fast during 2007. Similar to Europe, there was a sharp decrease in regional correlation during the second half of 2008 , followed by a very strong increase to levels well above 0.5 . Figure 5 shows signs of a higher correlation on average in Europe compared to the period of the Asian financial crisis, while Figure 6 indicates a strong increase in regional correlation in East Asia following the onset of the global financial crisis. It is also worth noting that the regional sample for East Asia includes China, a country with historically low levels of correlation with the rest of the region. We will get back to this in more detail below.

\section{[FIGURE 5 HERE]}

[FIGURE 6 HERE]

\section{c. Country-Regional Correlation}

Having discussed region-wide movements, we now take a look at country-regional correlation. We compute the average time-varying country-regional correlation for each of the ten 
countries in the two regions. The time-varying correlation patterns are presented in Figures 7 and 8. Focusing first on East Asia in Figure 7, the correlation patterns are similar for many of the countries. From a relatively low level of correlation, there was a strong increase during the initial crisis period. The increase was then followed by a brief drop in correlation before it increased drastically during the latter half of 2008. The overall pattern thus resembled that of the regional correlation. However, some country-regional correlations are warranted additional analysis. First, it is worth noting that China, a country with financial markets that are commonly regarded as insulated from the rest of the world, exhibited a strong increase in correlation during the whole period. This finding is supported in Johansson (2009b), where it is shown that China is actually experiencing an increasing level of market dependence with other countries and regions, including Asia. Second, markets commonly perceived as being among the most open in the world, such as Hong Kong and Singapore, do indeed exhibit among the highest correlations in the sample. Third, Japan, the largest market in terms of market capitalization in the region, exhibited a correlation pattern with a number of spikes after which correlation decreases significantly. Furthermore, Japan's overall correlation with the rest of the region is quite modest.

As noted earlier, Europe exhibited a higher average regional correlation over time compared to East Asia. Moreover, Figure 8 shows that the general pattern of correlation was similar in each of the ten European countries. All countries show evidence of high country-regional correlation patterns, except for a number of very short periods. Overall, a comparison between Figures 7 and 8 indicate that not only did Europe exhibit higher levels of correlation, but the country-regional patterns in Europe were also more similar. One explanation for this difference may be that East Asia, as opposed to Western Europe, includes a wider range of countries in terms of economic and financial development. For example, stock markets in Japan, Hong Kong and Singapore belong to the most developed in the world, 
while markets in countries such as China and Indonesia are considerably less developed. With such a wide range of equity markets in terms of development, we would thus expect a larger variety in correlation patterns in East Asia.

[FIGURE 7 HERE]

[FIGURE 8 HERE]

\section{d. Regional Tail Dependence}

Having established the regional correlation patterns during the different periods, we now analyze the regional tail dependence. First, we estimate the AR-t-EGARCH models as seen in Equations (11)-(13). The results from the maximum likelihood estimations are presented in Tables 2 and 3. Some results are warranted a closer look. First, most of the markets do not exhibit significant autocorrelation in their mean returns. Additional lag lengths were needed only for a few markets. Also, for most countries, it was enough to estimate an $\operatorname{EGARCH}(1,1)$ model. However, for a few of the markets in East Asia, an $\operatorname{EGARCH}(2,1)$ provided us with a better fit. Furthermore, almost all of the markets exhibit significant asymmetric features in volatility during this time period. The only exception is China. This indicates that the leverage effect is present in a majority of the markets. Finally, the distributions of most market returns in both regions are characterized by thick tails. This is evident in their respective $t$ distributions.

The regional tail dependencies in the two regions are shown in Figures 9 and 10. Looking first at East Asia, it seems that the financial crisis does not have a significant impact on tail dependence. There seems to be a small increase in tail dependence over the whole sample period, but it is not possible to deduct if there is a significant increase in regional tail dependence over the sample period. Similar to the regional correlation patterns, there is a decrease in regional tail dependence in 2007 followed by an increase in the end of 2008 . 
From Figure 10, we see that the regional tail dependence in Europe does not exhibit strong shifts during most of the sample period. Similar to East Asia, there is a decrease in tail dependence at the onset of the crisis, followed by a swift increase. There is also a sudden decrease in 2008, followed by an upward trend after the Lehman Brothers bankruptcy during the second half of 2008. Overall, the changes are not very pronounced, and the crisis does not seem to create a significant general change in tail dependence. Comparing tail dependence in the two regions, it is evident that average tail dependence in Europe is higher than that in Asia.

[FIGURE 9 HERE]

[FIGURE 10 HERE]

\section{e. Country-Regional Tail Dependence}

Having found that tail dependence remains quite stable over time in both regions, we now take a closer look at country-regional average tail dependence. The country-regional average tail dependence patterns are shown in Figures 11 and 12. Focusing first on Asia, all countries seem to exhibit relatively stable average tail dependence patterns. While the general patterns are stable throughout the sample, some countries exhibited significantly lower tail dependence with their respective region. For instance, China exhibited only modest average tail dependence patterns during the whole sample, fluctuating between 0.10 and 0.15 . Also, Singapore seemed to experience an increase in tail dependence from around 0.3 to approximately 0.4 .

Finally, looking at country-regional average tail dependence in Europe, the dependence structure was relatively stable across the sample. However, there was a significant decrease in tail dependence between several of the markets and the rest of Europe during the beginning of 2007. The fall in average tail dependence coincided with the beginning of the subprime crisis in the US. However, the decrease in the beginning of 2007 
was quickly reversed to the average level. Moreover, there was a decrease in 2008, once again followed by a fast increase to the average level.

[FIGURE 11 HERE]

[FIGURE 12 HERE]

\section{Conclusions}

The global financial crisis that began in the US property market and then spread to the real side of the economy has influenced financial markets around the world. In this paper, we extend the framework in Chakrabarti and Roll (2002) to analyze market movements and dependencies in Europe and East Asia before and during the crisis. A number of studies have shown that there are contagious effects across markets during times of financial turmoil. Given that the global crisis originated in the financial markets, it is reasonable to assume that there exist contagious effects in different regions that are related to the US in different ways. Furthermore, with an increasing level of financial globalization taking place, it would be natural to assume that comovements across regional markets are similar or even stronger today compared to periods of previous crises.

Our initial volatility analysis shows that market volatility in the two regions exhibited similar pattern with increasing levels around the outburst of the crisis in the US. There was also a very strong increase in regional volatility in both Europe and East Asia after the Lehman Brothers bankruptcy. Regional volatility increased the most in Europe, indicating that the region was more severely affected by the crisis. The correlation patterns show signs of very strong regional patterns in Europe and an increasing level of correlation in East Asia when the financial crisis spread from the US to the rest of the world. There was a sharp decrease in regional correlation in the second half of 2008 followed by a fast and large increase after the Lehman Brothers bankruptcy. Both regions exhibit higher levels of 
correlation compared to the period of the Asian financial crisis. A closer look at countryregional correlations also shows that some countries exhibited surprisingly high levels of comovements with their respective region. For instance, China, with an equity market often seen as insulated from the world markets, exhibited relatively high levels of correlation, especially after the onset of the financial crisis. Finally, the analysis show that the regional level of tail dependence was noticeably higher in Europe, but that East Asia also showed signs of considerable tail dependence across the sample. Swift changes in tail dependence occurred in 2008, but sudden decreases quickly reverted back to a mean level. Moreover, for a number of European markets, there was a sudden and large decrease in tail dependence at the beginning of the subprime crisis, again followed by sizeable increases.

Overall, the regional comovement patterns indicate that the markets in the two regions moved more closely together during the global financial crisis compared to the period of the Asian financial crisis analyzed in Chakrabarti and Roll (2002). Also, markets in Europe did seem to be affected more severely than the East Asian markets. The results have important implications for international investors who seek to diversify their regional portfolio holdings across country borders. While the crisis began as far away as the US, it quickly spread to other regions. This combined with a general increase in financial market integration indicate the decreasing benefits of diversification in regional portfolios. This initial analysis opens up for a number of future related research topics, including inter-regional dependence analysis and more detailed analyses of regional volatility spillover patterns. 


\section{References}

Baig, T., Goldfajn, I., 1998. Financial market contagion in the Asian crisis. IMF working paper, International Monetary Fund.

Bailey, W., Jagtiani, J., 1994. Foreign ownership restrictions and premiums for international investment: some evidence from the Thai capital market. Journal of Financial Economics 36, 57-88.

Bartram, S.M., Bodnar, G.M., 2009. No place to hide: the global crisis in equity markets in 2008/09. Journal of International Money and Finance, forthcoming.

Bekaert, G., Harvey, C.R., 1995. Time-varying world market integration. Journal of Finance 50, 403444.

Black, F., 1976. Studies in stock price volatility changes. Proceedings of the 1976 Business Meeting of the Business and Economics Statistics Section, American Statistical Association, 177-181.

Bollerslev, T., 1986. Generalized autoregressive conditional heteroskedasticity. Journal of Econometrics 31, 307-327.

Carrieri, F., Errunza, V., Hogan, K., 2007. Characterizing world market integration through time. Journal of Financial and Quantitative Analysis 42, 915-940.

Chakrabarti, R., Roll, R., 2002. East Asia and Europe during the 1997Asian collapse: a clinical study of a financial crisis, Journal of Financial Markets 5, 1-30.

Eichengreen, B., Park, Y.C., 2005. Financial Liberalization and Capital Market Integration in East Asia, In Park, Y.C., Ito, T., Wang, Y. (Eds.), A New Financial Market Structure for East Asia, Cheltenham: Edward Elgar.

Engle, R.F., 1982. Autoregressive conditional heteroskedasticity with estimates of the variance of U.K. inflation. Econometrica 64, 813-836.

Engle, R.F., 2002. Dynamic conditional correlation —a simple class of multivariate GARCH models. Journal of Business and Economic Statistics 20, 339-50.

Eun, C.S., Janakiramanan, S., 1986. A model of international asset pricing with a constraint on the foreign equity ownership. Journal of Finance 41, 897-914.

Forbes, K., Rigobon, R., 2002. No contagion, only interdependence: measuring stock market comovements. Journal of Finance 57, 2223-2261.

Harvey, C., 1991. The world price of covariance risk. Journal of Finance 46, 111-57.

Joe, H., 1997. Multivariate models and dependence concepts. London: Chapman \& Hall.

Johansson, A.C., 2008. Interdependencies among Asian bond markets, Journal of Asian Economics 19, 101-116.

Johansson, A.C., 2009a. An analysis of dynamic risk in the Greater China equity markets. Journal of Chinese Economic and Business Studies 7, 299-320. 
Johansson, A.C., 2009b. China's financial market integration with the world. China Economic Research Center Working Paper 2009-10.

Johansson, A.C., Ljungwall, C., 2009. Spillover effects among the Greater China stock markets. World Development 37, 839-851.

Jorion, P., Schwartz, E., 1986. Integration versus segmentation in the Canadian stock market. Journal of Finance 41, 603-613.

Nelsen, R.B., 1999. An introduction to copulas. New York: Springer-Verlag.

Nelson, D.B., 1991. Conditional heteroskedasticity in asset returns: a new approach. Econometrica 59, $347-370$.

Patton, A.J., 2006a. Modelling asymmetric exchange rate dependence. International Economic Review $47,527-555$.

Patton, A.J., 2006b. Estimation of multivariate models for time series of possibly different lengths. Journal of Applied Econometrics 21, 143-173.

Rodriguez, J.C., 2007. Measuring financial contagion: a copula approach. Journal of Empirical Finance 14, 401-23.

Sklar, A., 1959. Fonctions de r'epartition 'a n dimensions et leurs marges. Publications de l'Institut Statistique de l'Universit'e de Paris 8: 229-231.

Solnik, B., 1974. The international pricing of risk: An empirical investigation of the world capital market structure. Journal of Finance 29, 48-54.

Stehle, R., 1977. An empirical test of the alternative hypothesis of national and international pricing of risky assets. Journal of Finance 32, 493-502.

Stulz, R.M., 1981. On the effects of barriers to international investment. Journal of Finance 36, 923934. 
Table 1. Summary Statistics - Market Returns

\begin{tabular}{|c|c|c|c|c|c|c|c|c|c|c|}
\hline & China & Hong Kong & Indonesia & Japan & Korea & Malaysia & Philippines & Singapore & Taiwan & Thailand \\
\hline & \multicolumn{10}{|c|}{ Pre-Crisis Sample } \\
\hline Mean & 0.094 & 0.059 & 0.106 & 0.051 & 0.101 & 0.068 & 0.121 & 0.098 & 0.039 & 0.006 \\
\hline Maximum & 7.890 & 3.675 & 7.492 & 4.206 & 5.666 & 2.435 & 5.173 & 3.186 & 5.934 & 9.662 \\
\hline Minimum & -5.521 & -3.641 & -10.262 & -6.508 & -7.468 & -2.660 & -4.825 & -4.161 & -6.822 & -16.063 \\
\hline Std.Dev & 1.368 & 0.891 & 1.518 & 1.222 & 1.347 & 0.629 & 1.221 & 0.830 & 1.215 & 1.449 \\
\hline Skewness & 0.256 & -0.241 & -0.958 & -0.266 & -0.527 & 0.011 & -0.145 & -0.544 & -0.457 & -1.323 \\
\hline \multirow[t]{2}{*}{ Kurtosis } & 5.389 & 4.392 & 10.263 & 4.562 & 5.204 & 5.031 & 4.928 & 5.658 & 7.093 & 24.235 \\
\hline & \multicolumn{10}{|c|}{ Crisis Sample } \\
\hline Mean & 0.090 & 0.064 & 0.075 & 0.062 & 0.056 & 0.076 & 0.092 & 0.083 & 0.064 & 0.055 \\
\hline Maximum & 3.716 & 3.697 & 3.763 & 3.069 & 3.804 & 3.617 & 3.313 & 5.790 & 3.342 & 2.732 \\
\hline Minimum & -3.652 & -4.040 & -4.027 & -3.371 & -4.003 & -2.871 & -3.845 & -5.801 & -3.732 & -3.403 \\
\hline Std.Dev & 0.858 & 0.924 & 0.994 & 0.854 & 0.892 & 0.775 & 0.871 & 1.129 & 0.850 & 0.806 \\
\hline Skewness & -0.363 & -0.288 & -0.284 & -0.315 & -0.259 & 0.025 & -0.346 & -0.163 & -0.232 & -0.158 \\
\hline \multirow[t]{3}{*}{ Kurtosis } & 4.654 & 4.231 & 4.144 & 4.000 & 4.522 & 4.329 & 4.549 & 5.895 & 4.149 & 4.125 \\
\hline & Belgium & France & Germany & Italy & Netherlands & Portugal & Spain & Sweden & Switzerland & UK \\
\hline & \multicolumn{10}{|c|}{ Pre-Crisis Sample } \\
\hline Mean & -0.080 & -0.072 & -0.095 & -0.090 & -0.117 & -0.075 & -0.120 & -0.113 & -0.112 & -0.095 \\
\hline Maximum & 9.020 & 13.404 & 12.707 & 11.640 & 24.549 & 5.030 & 9.333 & 10.348 & 7.713 & 7.891 \\
\hline Minimum & -9.101 & -13.588 & -14.126 & -11.189 & -20.264 & -11.015 & -13.911 & -8.628 & -7.175 & -11.580 \\
\hline Std.Dev & 2.527 & 2.576 & 2.396 & 2.047 & 2.930 & 1.414 & 2.133 & 1.988 & 1.912 & 1.853 \\
\hline Skewness & -0.221 & 0.152 & -0.680 & -0.224 & -0.056 & -1.019 & -0.822 & -0.201 & -0.171 & -0.976 \\
\hline \multirow[t]{2}{*}{ Kurtosis } & 4.382 & 8.216 & 9.990 & 9.226 & 19.961 & 10.976 & 8.516 & 6.988 & 4.613 & 10.165 \\
\hline & \multicolumn{10}{|c|}{ Crisis Sample } \\
\hline Mean & -0.168 & -0.110 & -0.067 & -0.153 & -0.141 & -0.122 & -0.098 & -0.152 & -0.076 & -0.142 \\
\hline Maximum & 9.654 & 12.139 & 12.365 & 12.380 & 12.313 & 10.304 & 11.848 & 13.703 & 10.016 & 12.218 \\
\hline Minimum & -9.503 & -11.732 & -9.596 & -10.859 & -11.851 & -12.640 & -10.736 & -10.235 & -7.505 & -10.538 \\
\hline Std.Dev & 2.118 & 2.289 & 2.138 & 2.170 & 2.341 & 1.942 & 2.187 & 2.530 & 1.770 & 2.255 \\
\hline Skewness & -0.174 & 0.201 & 0.214 & 0.278 & -0.053 & -0.195 & 0.056 & 0.434 & 0.336 & 0.049 \\
\hline Kurtosis & 8.003 & 10.905 & 11.543 & 11.313 & 10.960 & 11.587 & 10.337 & 8.415 & 8.902 & 10.369 \\
\hline
\end{tabular}


Table 2. Conditional Volatility Estimations East Asia

\begin{tabular}{|c|c|c|c|c|c|c|c|c|c|c|}
\hline & China & Hong Kong & Indonesia & Japan & Korea & Malaysia & Philippines & Singapore & Taiwan & Thailand \\
\hline$\mu_{i}$ & $\begin{array}{l}0.077^{*} \\
(0.038)\end{array}$ & $\begin{array}{l}0.059^{*} \\
(0.025)\end{array}$ & $\begin{array}{c}0.109 * * \\
(0.034)\end{array}$ & $\begin{array}{c}0.004 \\
(0.032)\end{array}$ & $\begin{array}{c}0.126^{* *} \\
(0.033)\end{array}$ & $\begin{array}{c}0.028 \\
(0.017)\end{array}$ & $\begin{array}{l}0.074^{*} \\
(0.033)\end{array}$ & $\begin{array}{c}0.090^{* *} \\
(0.024)\end{array}$ & $\begin{array}{l}0.061^{*} \\
(0.030)\end{array}$ & $\begin{array}{c}0.028 \\
(0.032)\end{array}$ \\
\hline$\phi_{i} 1$ & $\begin{array}{l}-0.004 \\
(0.026)\end{array}$ & $\begin{array}{l}-0.016 \\
(0.023)\end{array}$ & $\begin{array}{r}0.125^{* *} \\
(0.028)\end{array}$ & $\begin{array}{c}-0.096^{* *} \\
(0.030)\end{array}$ & $\begin{array}{c}0.046 \\
(0.024)\end{array}$ & $\begin{array}{c}0.126^{* *} \\
(0.027)\end{array}$ & $\begin{array}{l}0.097^{* *} \\
(0.029)\end{array}$ & $\begin{array}{c}0.02 \\
(0.030)\end{array}$ & $\begin{array}{l}0.052^{*} \\
(0.023)\end{array}$ & $\begin{array}{l}0.058^{*} \\
(0.028)\end{array}$ \\
\hline$\phi_{i 2}$ & $\begin{array}{c}0.015 \\
(0.026)\end{array}$ & & & & & & & & & $\begin{array}{l}0.067^{*} \\
(0.027)\end{array}$ \\
\hline$\phi_{i} 3$ & $\begin{array}{l}0.059^{*} \\
(0.027)\end{array}$ & & & & & & & & & $\begin{array}{l}-0.005 \\
(0.027)\end{array}$ \\
\hline$\phi_{i} 4$ & & & & & & & & & & $\begin{array}{l}-0.008 \\
(0.028)\end{array}$ \\
\hline$\phi_{i} 5$ & & & & & & & & & & $\begin{array}{l}-0.006 \\
(0.026)\end{array}$ \\
\hline$\phi_{i} 6$ & & & & & & & & & & $\begin{array}{l}-0.056^{*} \\
(0.026)\end{array}$ \\
\hline$\omega_{i}$ & $\begin{array}{c}-0.088^{* *} \\
(0.017)\end{array}$ & $\begin{array}{c}-0.125^{* *} \\
(0.020)\end{array}$ & $\begin{array}{c}-0.130^{* *} \\
(0.032)\end{array}$ & $\begin{array}{c}-0.121 * * \\
(0.022)\end{array}$ & $\begin{array}{c}-0.111^{* *} \\
(0.024)\end{array}$ & $\begin{array}{c}-0.155^{* *} \\
(0.024)\end{array}$ & $\begin{array}{c}-0.179 * * \\
(0.031)\end{array}$ & $\begin{array}{c}-0.143 * * \\
(0.025)\end{array}$ & $\begin{array}{c}-0.114 * * \\
(0.022)\end{array}$ & $\begin{array}{c}-0.101 * * \\
(0.025)\end{array}$ \\
\hline$\alpha_{i 1}$ & $\begin{array}{c}0.145^{* *} \\
(0.028)\end{array}$ & $\begin{array}{l}-0.116 \\
(0.065)\end{array}$ & $\begin{array}{c}0.289 * * \\
(0.045)\end{array}$ & $\begin{array}{c}0.171^{* *} \\
(0.029)\end{array}$ & $\begin{array}{l}-0.054 \\
(0.064)\end{array}$ & $\begin{array}{c}0.204 * * \\
(0.032)\end{array}$ & $\begin{array}{c}0.301 * * \\
(0.046)\end{array}$ & $\begin{array}{c}0.186^{* *} \\
(0.033)\end{array}$ & $\begin{array}{l}-0.160^{*} \\
(0.071)\end{array}$ & $\begin{array}{c}0.178 * * \\
(0.035)\end{array}$ \\
\hline$\alpha_{i 2}$ & & $\begin{array}{c}0.297 * * \\
(0.069)\end{array}$ & & & $\begin{array}{c}0.240 * * \\
(0.067)\end{array}$ & & & & $\begin{array}{c}0.340 * * \\
(0.072)\end{array}$ & \\
\hline$\beta_{i 1}$ & $\begin{array}{c}0.987^{* *} \\
(0.006)\end{array}$ & $\begin{array}{c}0.984 * * \\
(0.005)\end{array}$ & $\begin{array}{c}0.903 * * \\
(0.018)\end{array}$ & $\begin{array}{c}0.975^{* *} \\
(0.007)\end{array}$ & $\begin{array}{c}0.961 * * \\
(0.007)\end{array}$ & $\begin{array}{c}0.981 * * \\
(0.006)\end{array}$ & $\begin{array}{c}0.935^{* *} \\
(0.017)\end{array}$ & $\begin{array}{c}0.979 * * \\
(0.006)\end{array}$ & $\begin{array}{c}0.967 * * \\
(0.009)\end{array}$ & $\begin{array}{c}0.945^{* *} \\
(0.013)\end{array}$ \\
\hline$\gamma_{i 1}$ & $\begin{array}{l}-0.024 \\
(0.015)\end{array}$ & $\begin{array}{c}-0.083 * * \\
(0.017)\end{array}$ & $\begin{array}{c}-0.190 * * \\
(0.033)\end{array}$ & $\begin{array}{c}-0.103 * * \\
(0.018)\end{array}$ & $\begin{array}{c}-0.148 * * \\
(0.023)\end{array}$ & $\begin{array}{c}-0.051^{* *} \\
(0.020)\end{array}$ & $\begin{array}{l}-0.057^{*} \\
(0.026)\end{array}$ & $\begin{array}{c}-0.088^{* *} \\
(0.021)\end{array}$ & $\begin{array}{c}-0.082 * * \\
(0.020)\end{array}$ & $\begin{array}{c}-0.093 * * \\
(0.023)\end{array}$ \\
\hline$v_{i}$ & $\begin{array}{l}4.480^{* *} \\
(0.664)\end{array}$ & $\begin{array}{c}5.368^{* *} \\
(1.053)\end{array}$ & $\begin{array}{l}4.444^{* *} \\
(0.505)\end{array}$ & $\begin{array}{c}16.959 * * \\
(7.502)\end{array}$ & $\begin{array}{c}5.812 * * \\
(1.083)\end{array}$ & $\begin{array}{c}4.731 * * \\
(0.676)\end{array}$ & $\begin{array}{r}5.619^{* *} \\
(0.972)\end{array}$ & $\begin{array}{c}8.426^{* *} \\
(1.878)\end{array}$ & $\begin{array}{l}5.604 * * \\
(1.042)\end{array}$ & $\begin{array}{c}5.196^{* *} \\
(0.577)\end{array}$ \\
\hline$Q(10)$ & $\begin{array}{l}13.179 \\
{[0.214]}\end{array}$ & $\begin{array}{c}8.212 \\
{[0.608]}\end{array}$ & $\begin{array}{l}14.420 \\
{[0.155]}\end{array}$ & $\begin{array}{l}10.396 \\
{[0.406]}\end{array}$ & $\begin{array}{c}7.266 \\
{[0.700]}\end{array}$ & $\begin{array}{l}18.220 \\
{[0.051]}\end{array}$ & $\begin{array}{l}12.613 \\
{[0.246]}\end{array}$ & $\begin{array}{l}10.057 \\
{[0.435]}\end{array}$ & $\begin{array}{l}10.100 \\
{[0.432]}\end{array}$ & $\begin{array}{c}5.888 \\
{[0.825]}\end{array}$ \\
\hline$Q^{2}(10)$ & $\begin{array}{c}7.955 \\
{[0.633]}\end{array}$ & $\begin{array}{l}16.136 \\
{[0.096]}\end{array}$ & $\begin{array}{c}1.142 \\
{[1.000]}\end{array}$ & $\begin{array}{l}12.826 \\
{[0.234]}\end{array}$ & $\begin{array}{l}26.736 \\
{[0.118]}\end{array}$ & $\begin{array}{c}5.926 \\
{[0.821]}\end{array}$ & $\begin{array}{c}3.862 \\
{[0.953]}\end{array}$ & $\begin{array}{l}14.885 \\
{[0.136]}\end{array}$ & $\begin{array}{c}13.843 \\
{[0.180]}\end{array}$ & $\begin{array}{c}5.346 \\
{[0.867]}\end{array}$ \\
\hline
\end{tabular}

Note: * and ** indicate statistical significance at the $5 \%$ and $1 \%$ level, respectively. $Q(10)$ and $Q^{2}(10)$ represent Ljung-Box statistics for serial correlation up to the 10th order for the standardized residuals and standardized squared residuals, respectively. Standard errors are given in parentheses. Numbers in brackets for the Ljung-Box statistics are $p$-values. 
Table 3. Conditional Volatility Estimations Europe

\begin{tabular}{|c|c|c|c|c|c|c|c|c|c|c|}
\hline & Belgium & France & Germany & Italy & Netherlands & Portugal & Spain & Sweden & Switzerland & UK \\
\hline$\mu_{i}$ & $\begin{array}{c}0.079 * * \\
(0.025)\end{array}$ & $\begin{array}{c}0.046 \\
(0.026)\end{array}$ & $\begin{array}{c}0.076^{* *} \\
(0.027)\end{array}$ & $\begin{array}{l}0.052 * \\
(0.024)\end{array}$ & $\begin{array}{c}0.042 \\
(0.024)\end{array}$ & $\begin{array}{l}0.055^{*} \\
(0.022)\end{array}$ & $\begin{array}{c}0.075^{* *} \\
(0.024)\end{array}$ & $\begin{array}{c}0.050 \\
(0.031)\end{array}$ & $\begin{array}{c}0.029 \\
(0.024)\end{array}$ & $\begin{array}{c}0.041 \\
(0.023)\end{array}$ \\
\hline$\phi_{i} 1$ & $\begin{array}{c}0.003 \\
(0.029)\end{array}$ & $\begin{array}{l}-0.054 \\
(0.029)\end{array}$ & $\begin{array}{l}-0.013 \\
(0.029)\end{array}$ & $\begin{array}{l}-0.042 \\
(0.029)\end{array}$ & $\begin{array}{c}0.005 \\
(0.028)\end{array}$ & $\begin{array}{c}0.021 \\
(0.027)\end{array}$ & $\begin{array}{c}0.006 \\
(0.028)\end{array}$ & $\begin{array}{l}-0.013 \\
(0.027)\end{array}$ & $\begin{array}{l}-0.028 \\
(0.028)\end{array}$ & $\begin{array}{l}-0.069^{*} \\
(0.028)\end{array}$ \\
\hline$\phi_{i} 2$ & & & & & & $\begin{array}{c}0.048 \\
(0.028)\end{array}$ & & & & \\
\hline$\phi_{i} 3$ & & & & & & $\begin{array}{c}0.011 \\
(0.028)\end{array}$ & & & & \\
\hline$\omega_{i}$ & $\begin{array}{c}-0.134^{* *} \\
(0.023)\end{array}$ & $\begin{array}{c}-0.010^{* *} \\
(0.023)\end{array}$ & $\begin{array}{c}-0.108^{* *} \\
(0.024)\end{array}$ & $\begin{array}{c}-0.126^{* *} \\
(0.023)\end{array}$ & $\begin{array}{c}-0.106^{* *} \\
(0.021)\end{array}$ & $\begin{array}{c}-0.112 * * \\
(0.022)\end{array}$ & $\begin{array}{c}-0.113^{* *} \\
(0.022)\end{array}$ & $\begin{array}{c}-0.080 * * \\
(0.020)\end{array}$ & $\begin{array}{c}-0.121^{* *} \\
(0.023)\end{array}$ & $\begin{array}{c}-0.132 * * \\
(0.024)\end{array}$ \\
\hline$\alpha_{i}{ }_{1}$ & $\begin{array}{c}0.171^{* *} \\
(0.029)\end{array}$ & $\begin{array}{l}0.132 * * \\
(0.030)\end{array}$ & $\begin{array}{r}0.146^{* *} \\
(0.032)\end{array}$ & $\begin{array}{l}0.162 * * \\
(0.031)\end{array}$ & $\begin{array}{c}0.136^{* *} \\
(0.027)\end{array}$ & $\begin{array}{c}0.146^{* *} \\
(0.029)\end{array}$ & $\begin{array}{r}0.149 * * \\
(0.029)\end{array}$ & $\begin{array}{r}0.116^{* *} \\
(0.027)\end{array}$ & $\begin{array}{c}0.153^{* *} \\
(0.029)\end{array}$ & $\begin{array}{l}0.167 * * \\
(0.031)\end{array}$ \\
\hline$\alpha_{i 2}$ & & & & & & & & & & \\
\hline$\beta_{i 1}$ & $\begin{array}{c}0.976^{* *} \\
(0.006)\end{array}$ & $\begin{array}{c}0.978^{* *} \\
(0.005)\end{array}$ & $\begin{array}{c}0.974 * * \\
(0.006)\end{array}$ & $\begin{array}{c}0.978^{* *} \\
(0.006)\end{array}$ & $\begin{array}{c}0.979 * * \\
(0.005)\end{array}$ & $\begin{array}{c}0.981 * * \\
(0.005)\end{array}$ & $\begin{array}{c}0.979 * * \\
(0.005)\end{array}$ & $\begin{array}{c}0.980 * * \\
(0.005)\end{array}$ & $\begin{array}{c}0.983 * * \\
(0.005)\end{array}$ & $\begin{array}{c}0.979 * * \\
(0.005)\end{array}$ \\
\hline$\gamma_{i} 1$ & $\begin{array}{c}-0.107 * * \\
(0.019)\end{array}$ & $\begin{array}{c}-0.119^{* *} \\
(0.020)\end{array}$ & $\begin{array}{c}-0.111^{* *} \\
(0.020)\end{array}$ & $\begin{array}{c}-0.090 * * \\
(0.020)\end{array}$ & $\begin{array}{c}-0.124 * * \\
(0.019)\end{array}$ & $\begin{array}{c}-0.074 * * \\
(0.017)\end{array}$ & $\begin{array}{c}-0.106^{* *} \\
(0.018)\end{array}$ & $\begin{array}{c}-0.123 * * \\
(0.020)\end{array}$ & $\begin{array}{c}-0.085^{* *} \\
(0.019)\end{array}$ & $\begin{array}{c}-0.115 * * \\
(0.022)\end{array}$ \\
\hline$v_{i}$ & $\begin{array}{l}10.314 \\
(2.877)\end{array}$ & $\begin{array}{c}10.418 * * \\
(2.973)\end{array}$ & $\begin{array}{l}8.259^{* *} \\
(2.028)\end{array}$ & $\begin{array}{c}10.109 * * \\
(2.994)\end{array}$ & $\begin{array}{c}13.085^{* *} \\
(5.068)\end{array}$ & $\begin{array}{c}6.611^{* *} \\
(1.326)\end{array}$ & $\begin{array}{r}7.427^{* *} \\
(1.593)\end{array}$ & $\begin{array}{l}8.605^{* *} \\
(2.184)\end{array}$ & $\begin{array}{l}16.007^{*} \\
(7.285)\end{array}$ & $\begin{array}{c}11.612^{* *} \\
(3.445)\end{array}$ \\
\hline$Q(10)$ & $\begin{array}{c}9.637 \\
{[0.473]}\end{array}$ & $\begin{array}{l}12.576 \\
{[0.248]}\end{array}$ & $\begin{array}{c}9.283 \\
{[0.505]}\end{array}$ & $\begin{array}{c}8.303 \\
{[0.599]}\end{array}$ & $\begin{array}{l}10.373 \\
{[0.408]}\end{array}$ & $\begin{array}{l}18.411 \\
{[0.072]}\end{array}$ & $\begin{array}{l}11.263 \\
{[0.337]}\end{array}$ & $\begin{array}{c}9.449 \\
{[0.490]}\end{array}$ & $\begin{array}{l}10.153 \\
{[0.427]}\end{array}$ & $\begin{array}{c}8.650 \\
{[0.566]}\end{array}$ \\
\hline$Q^{2}(10)$ & $\begin{array}{l}13.523 \\
{[0.196]}\end{array}$ & $\begin{array}{c}8.400 \\
{[0.590]}\end{array}$ & $\begin{array}{c}8.997 \\
{[0.532]}\end{array}$ & $\begin{array}{c}6.363 \\
{[0.784]}\end{array}$ & $\begin{array}{l}12.679 \\
{[0.242]}\end{array}$ & $\begin{array}{c}6.681 \\
{[0.755]}\end{array}$ & $\begin{array}{c}9.834 \\
{[0.455]}\end{array}$ & $\begin{array}{c}9.662 \\
{[0.471]}\end{array}$ & $\begin{array}{c}4.730 \\
{[0.908]}\end{array}$ & $\begin{array}{c}8.169 \\
{[0.612]}\end{array}$ \\
\hline
\end{tabular}

Note: * and ** indicate statistical significance at the $5 \%$ and $1 \%$ level, respectively. $Q(10)$ and $Q^{2}(10)$ represent Ljung-Box statistics for serial correlation up to the 10th order for the standardized residuals and standardized squared residuals, respectively. Standard errors are given in parentheses. Numbers in brackets for the Ljung-Box statistics are $p$-values. 
Figure 1. Regional Volatility East Asia

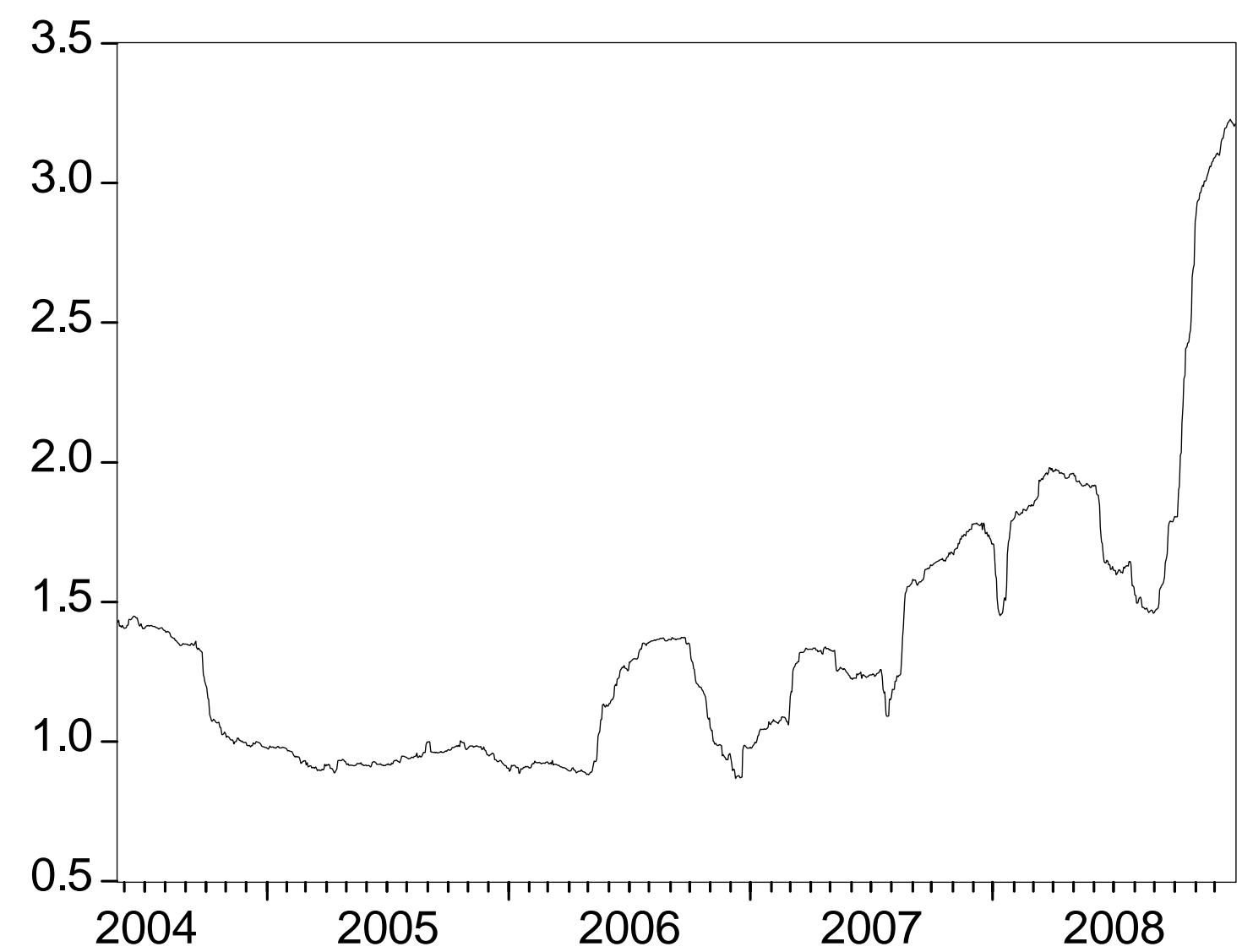


Figure 2. Regional Volatility Europe

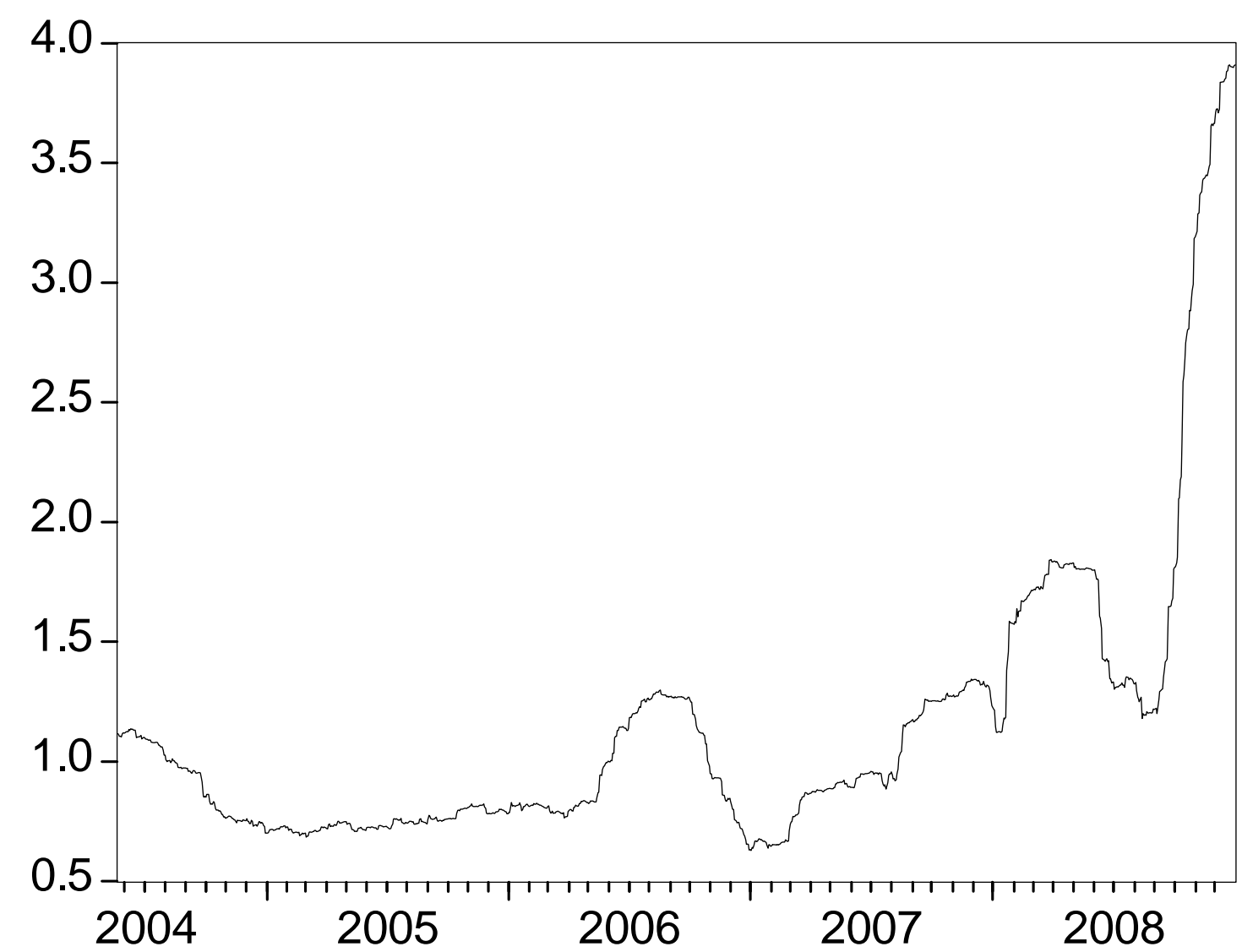


Figure 3. Regional Covariance East Asia

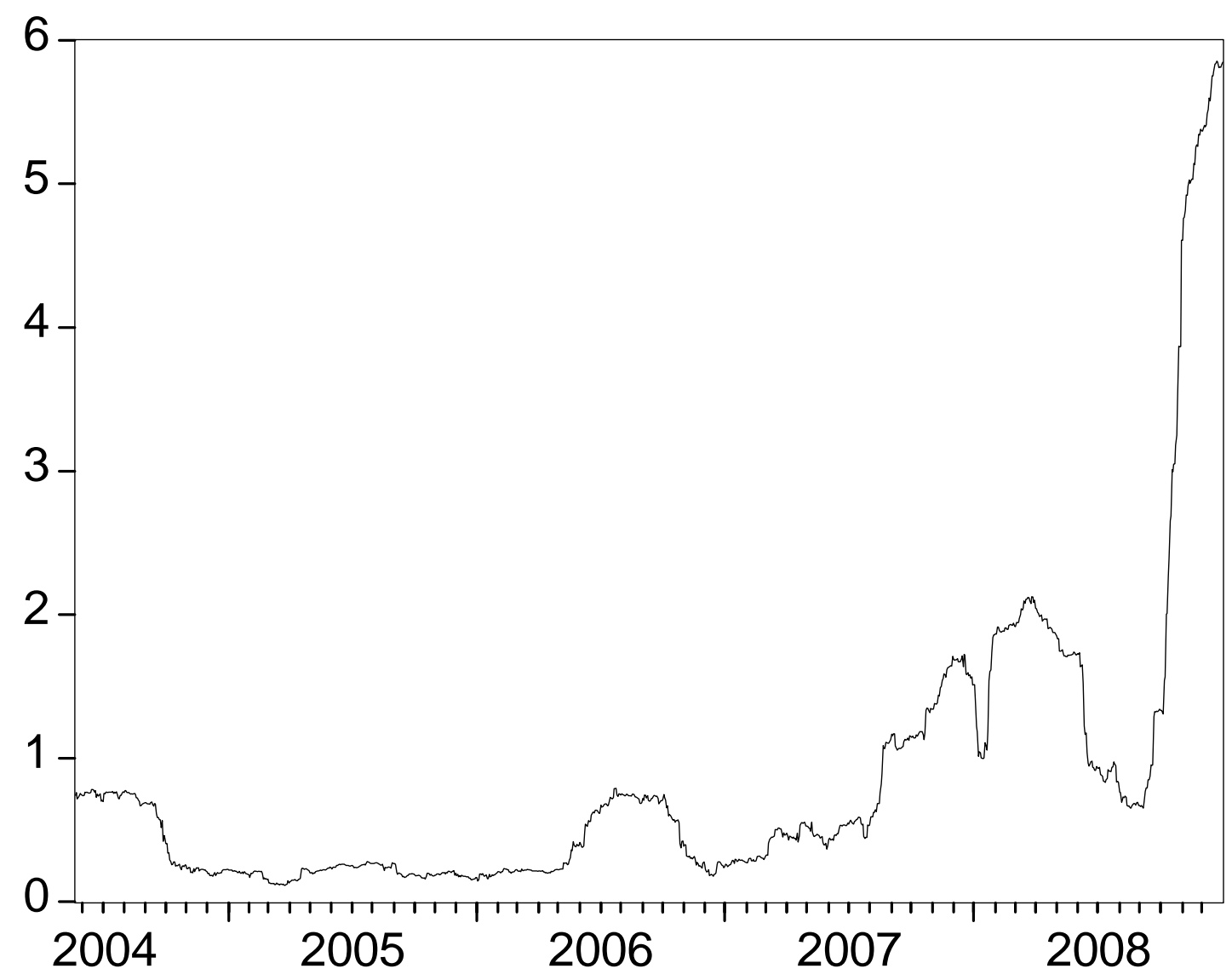


Figure 4. Regional Covariance Europe

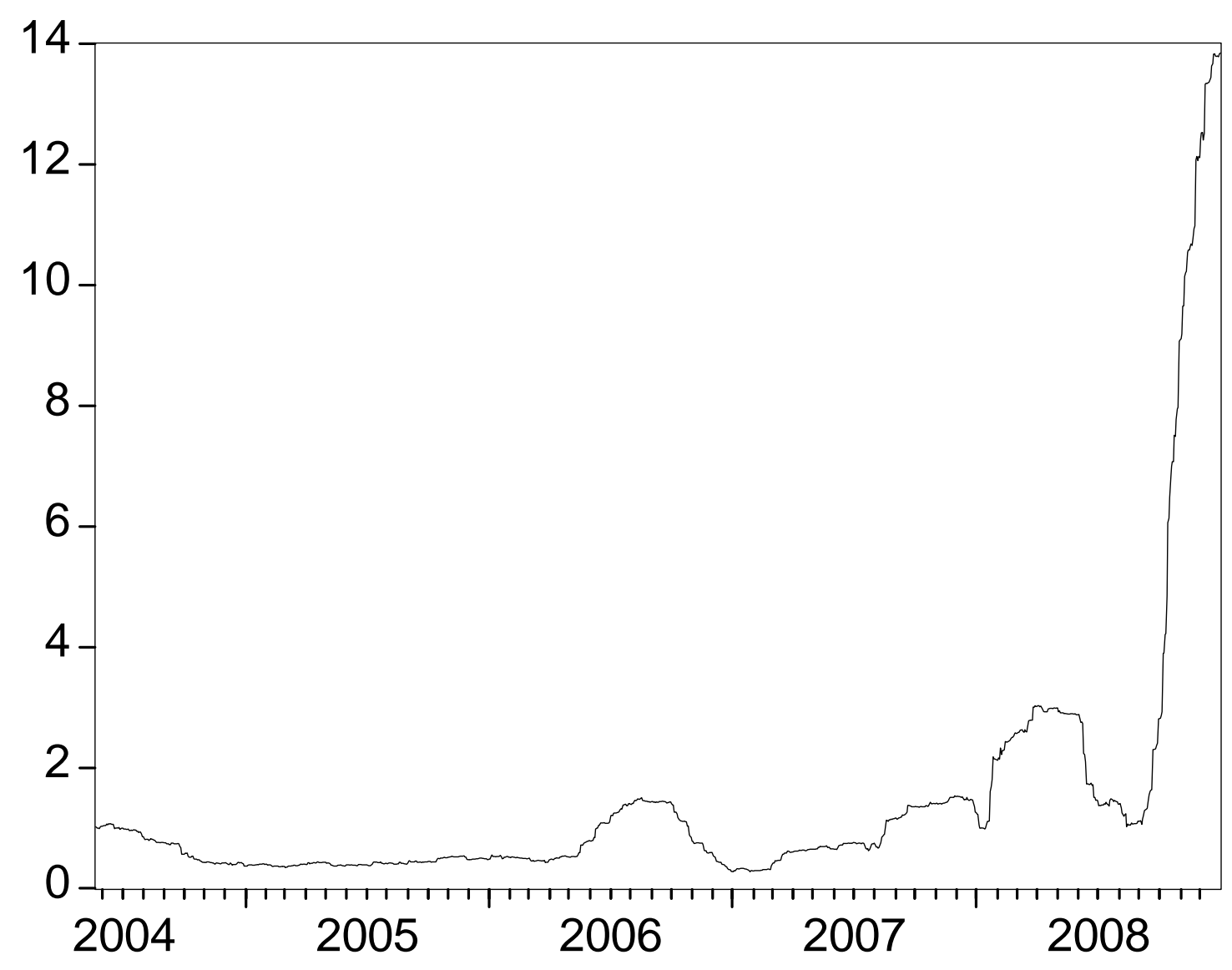


Figure 5. Regional Correlation Asia

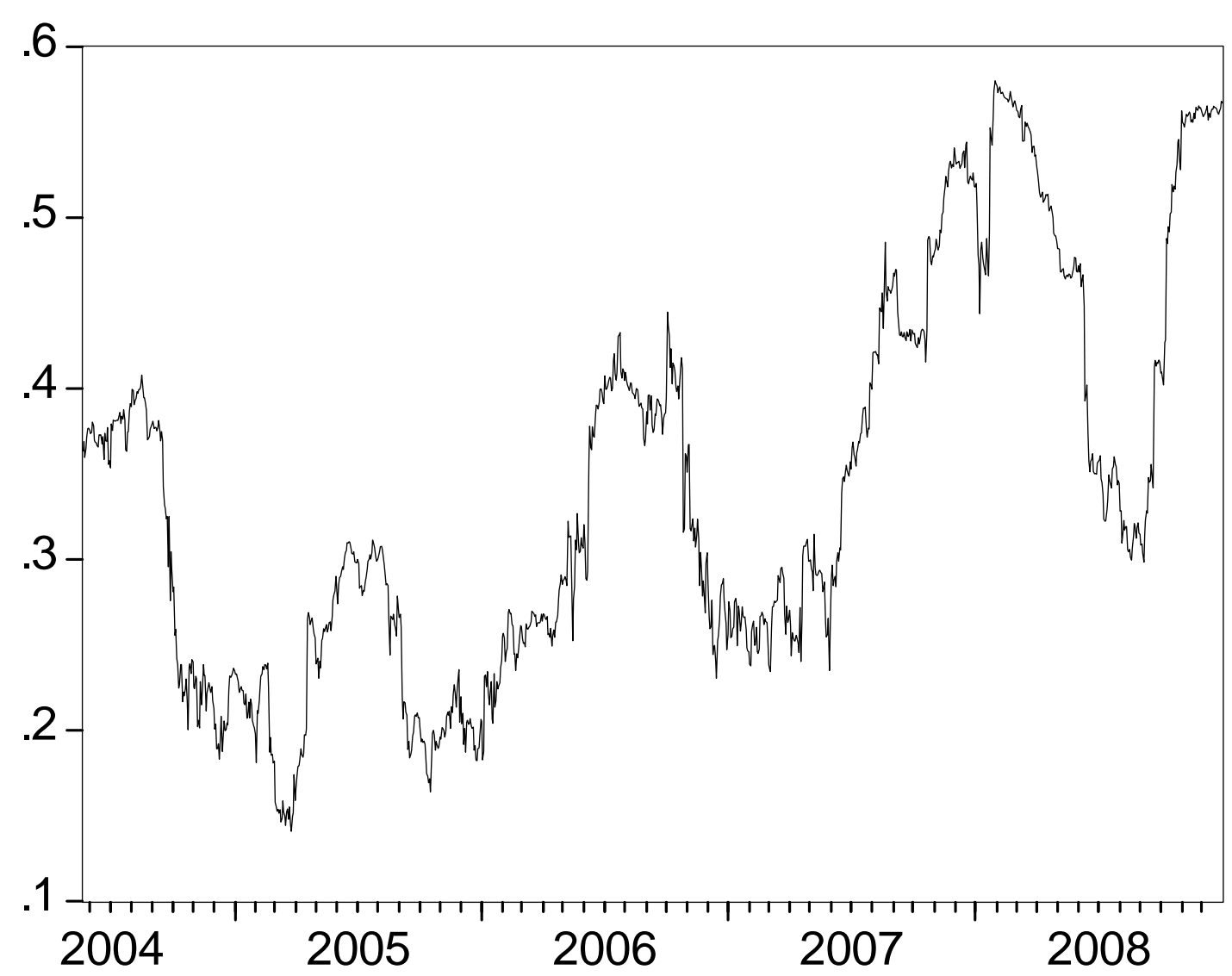


Figure 6. Regional Correlation Europe

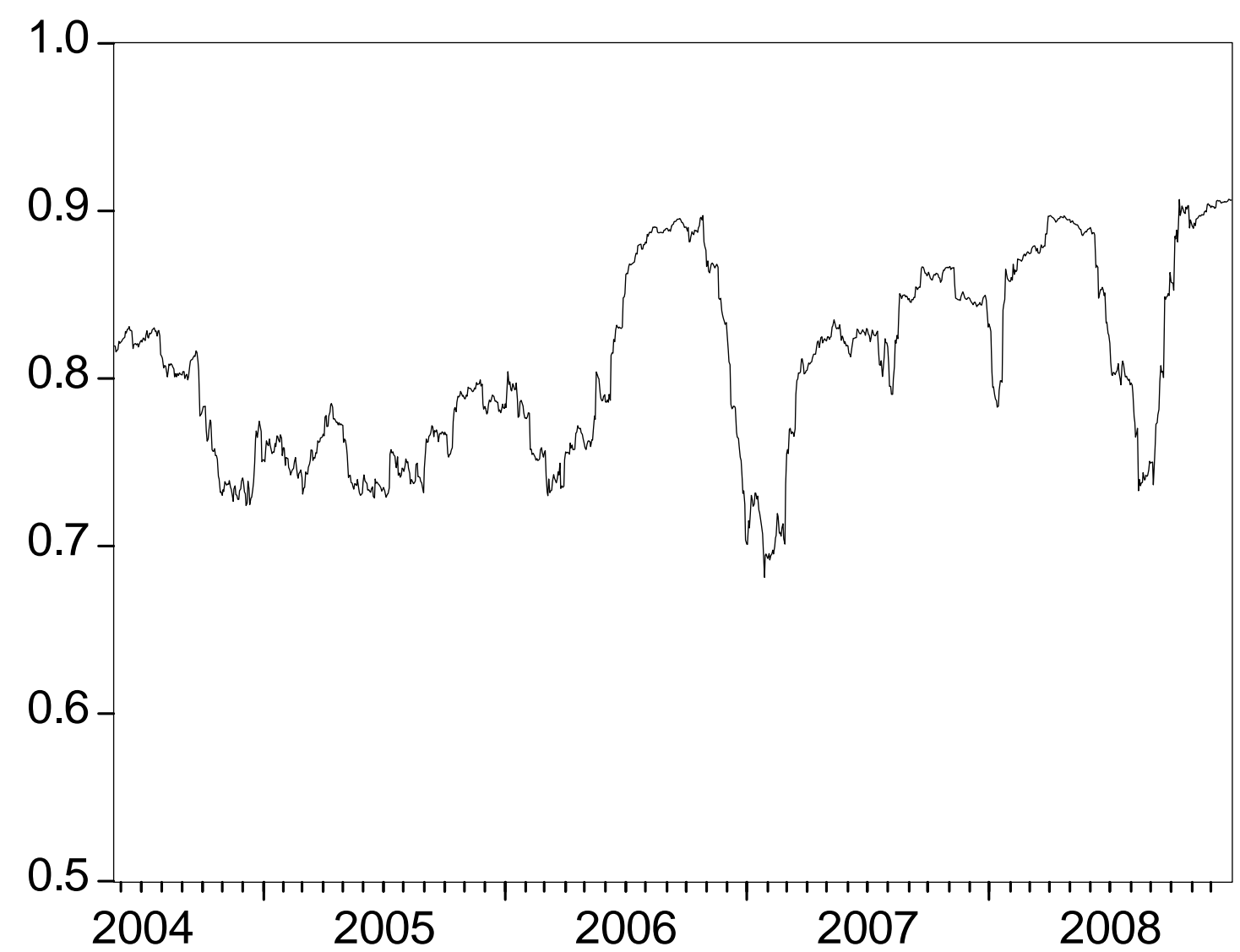


Figure 7. Country-Regional Correlation East Asia
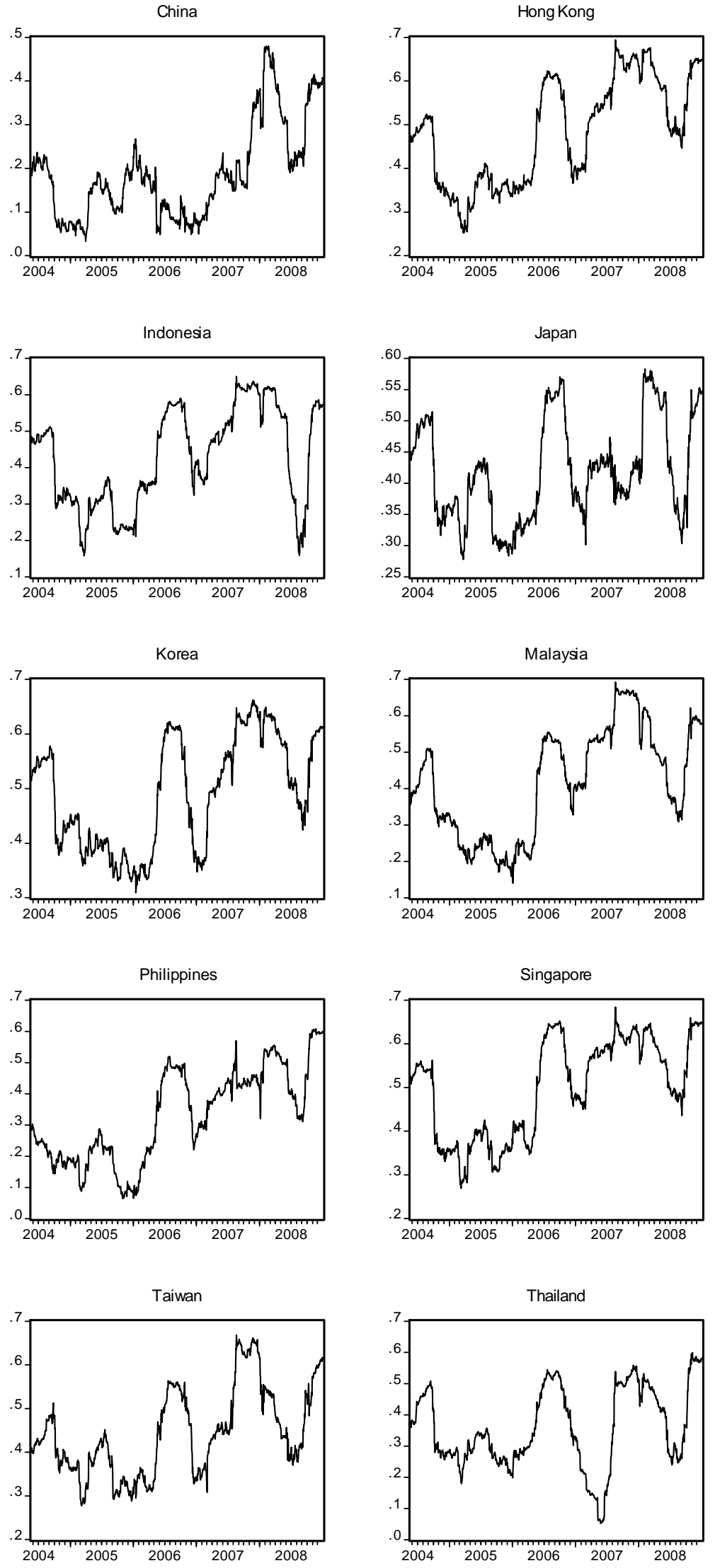
Figure 8. Country-Regional Correlation Europe
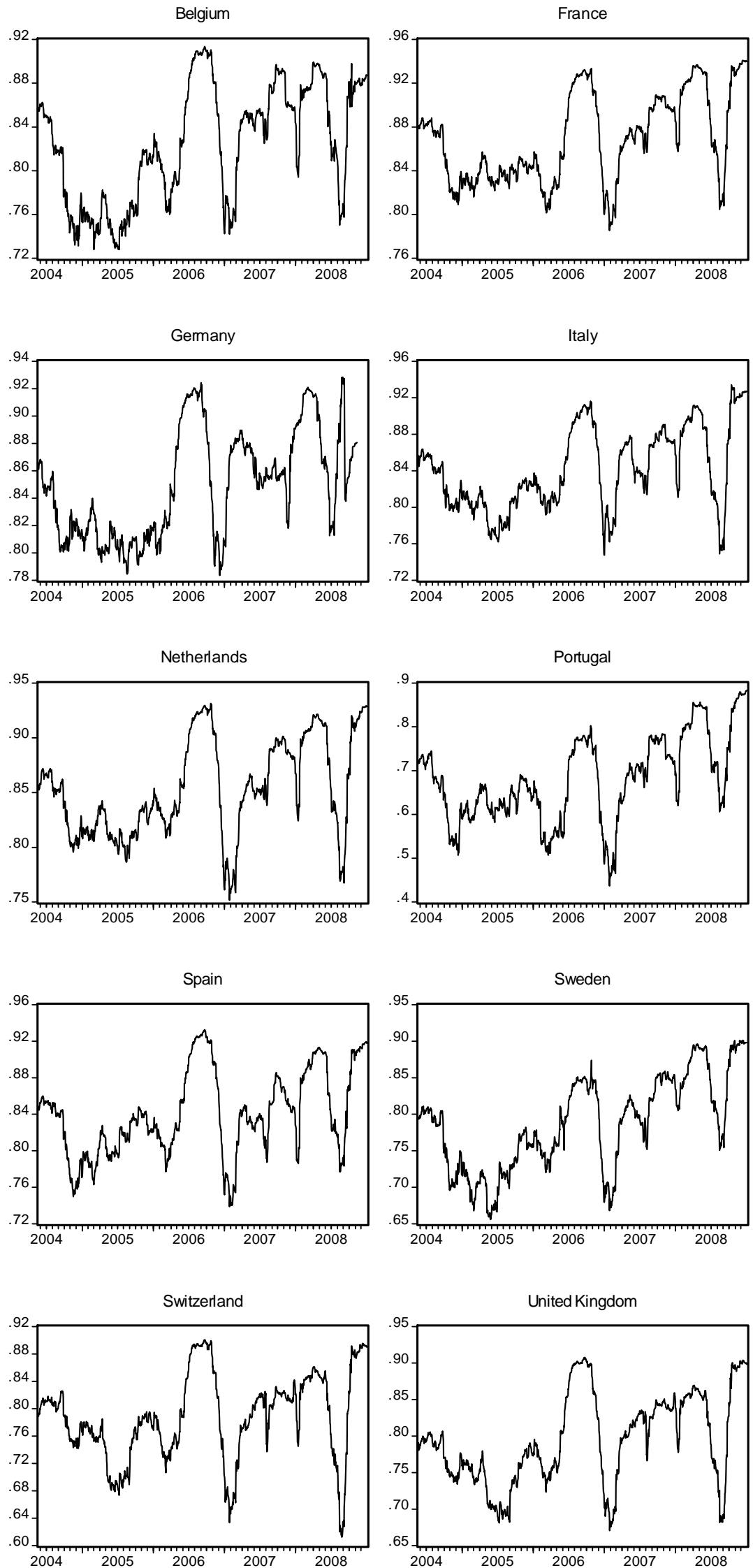
Figure 9. Regional Tail Dependence East Asia

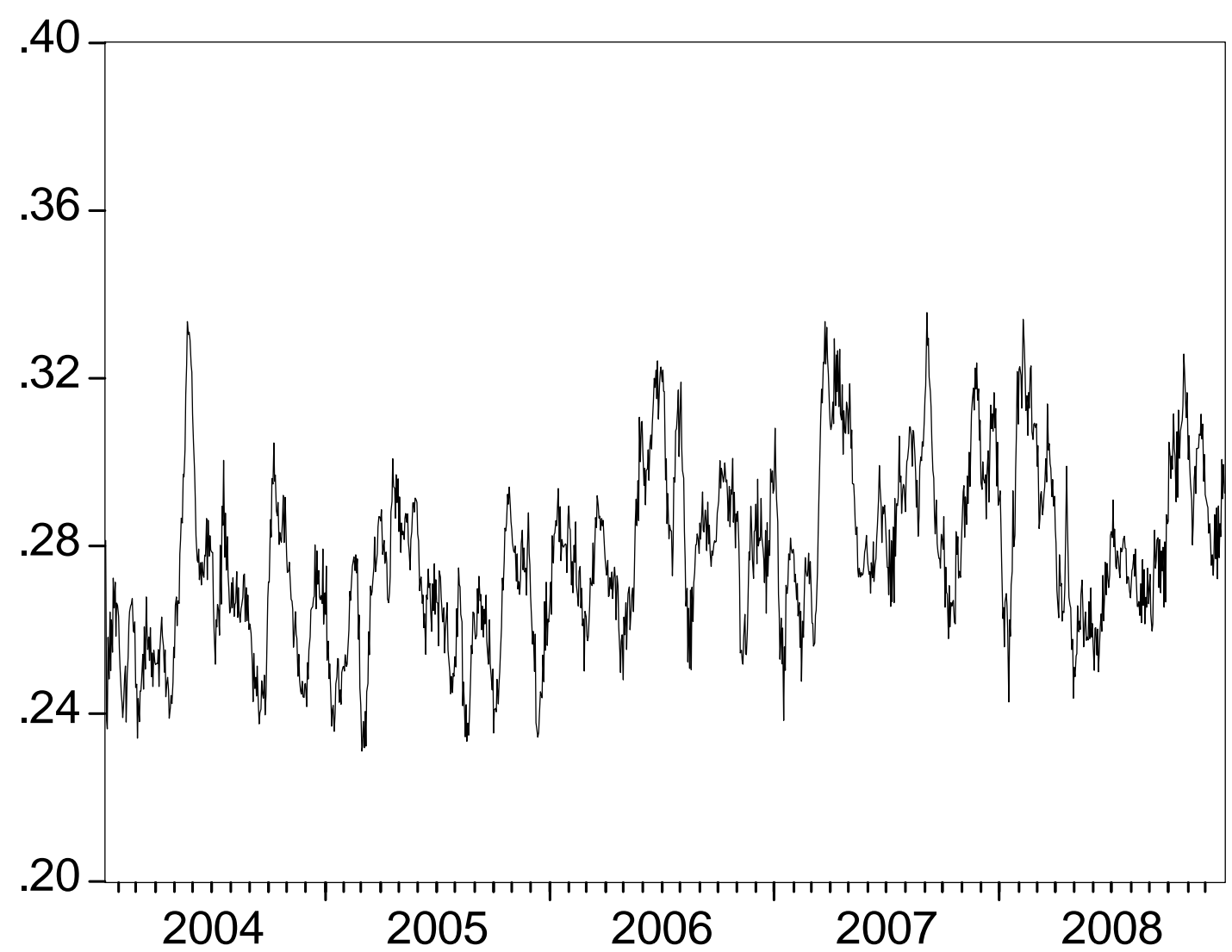


Figure 10. Regional Tail Dependence Europe

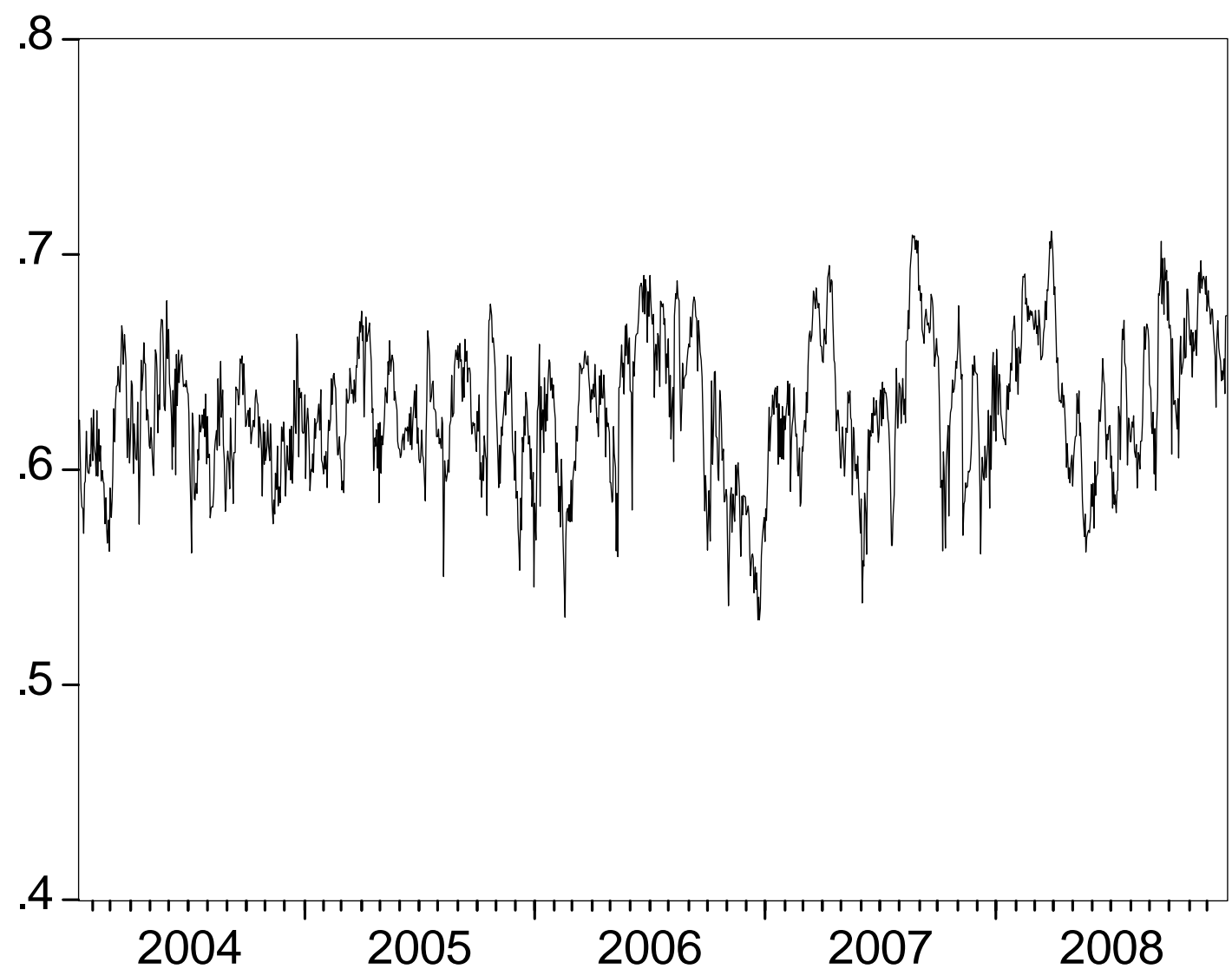


Figure 11. Country-Regional Tail Dependence East Asia
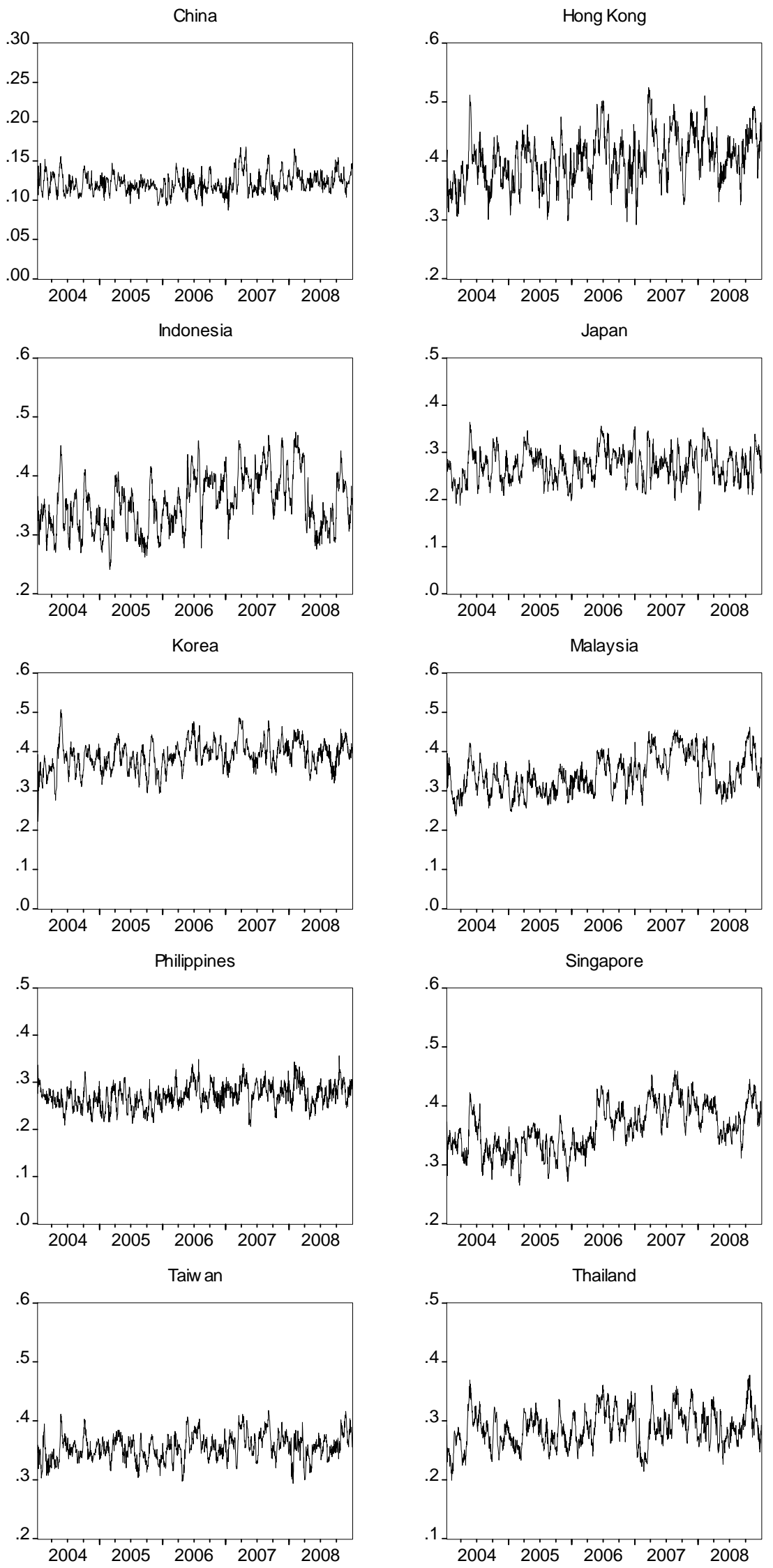
Figure 12. Country-Regional Tail Dependence Europe
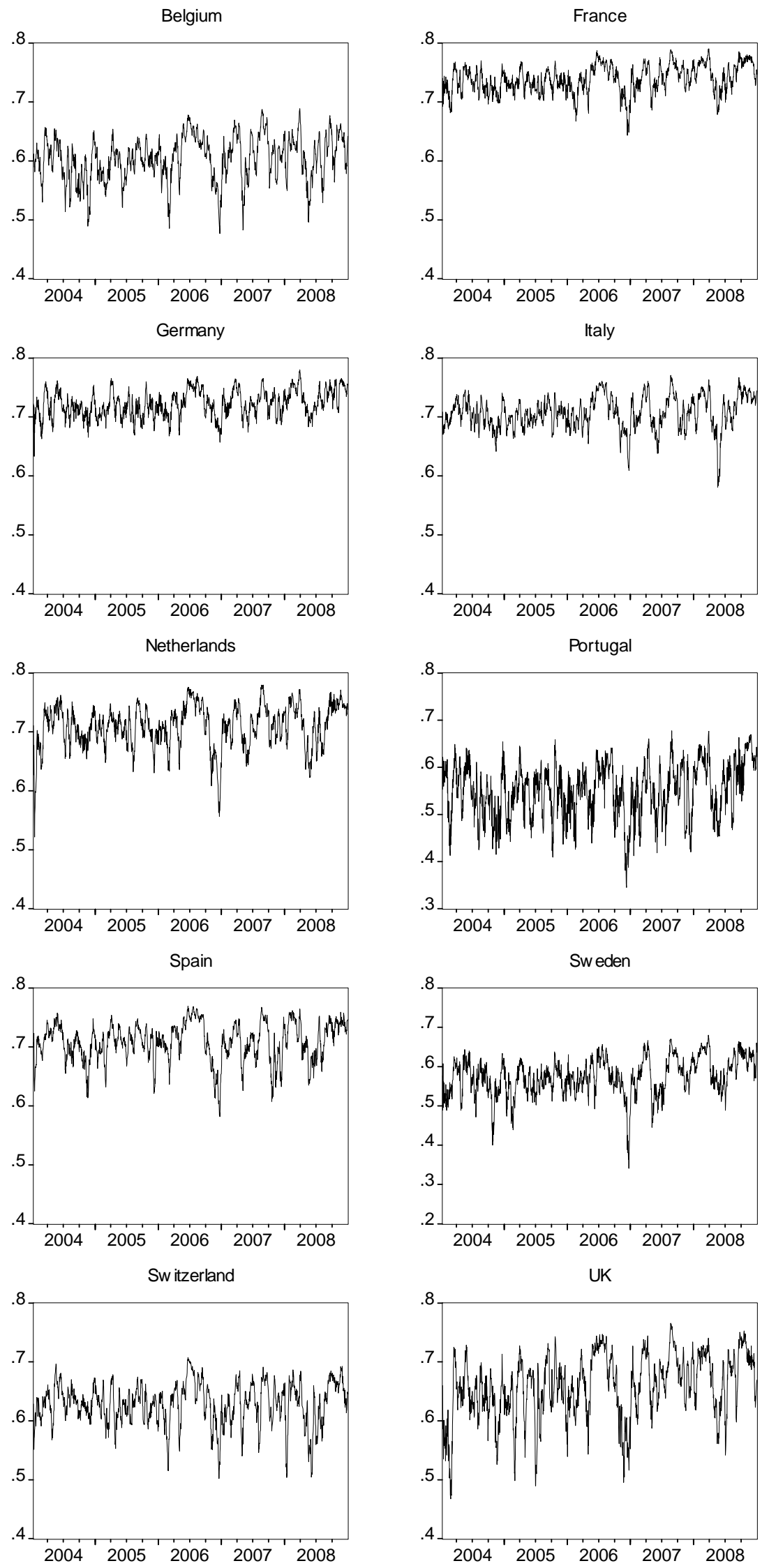